\title{
Airflow obstruction is associated with increased smooth muscle extracellular matrix
}

\author{
To the Editor:
}

Increased thickness of the airway smooth muscle (ASM) layer is a characteristic feature of airway remodelling in both asthma and chronic obstructive pulmonary disease (COPD) $[1,2]$. The composition of the ASM layer has been well studied in asthma where the increased thickness of the ASM layer is due to hypertrophy and/or hyperplasia [3-5] of ASM cells. These changes are associated with a concomitant increase in absolute volumes of both ASM and extracellular matrix (ECM), without changes in their relative volume fractions [5]. Although ASM cell hypertrophy has been reported in the large airways of patients with COPD [6], these findings did not exclude the effect of an increase in the volume fraction of ECM on the estimated average volume of the ASM cells [7].

Increased thickness of the ASM layer is a prominent feature of airway wall remodelling in COPD $[1,8]$. Only two studies have quantified the fractional amounts of smooth muscle and ECM within the ASM layer in COPD $[9,10]$. These studies have quantified the ECM within the ASM layer of peripheral airways of subjects with COPD, showing increased staining intensity of laminin [9] and fibronectin [10]. ANNONI et al. [10] also examined the relative areas of ECM within the ASM layer, an advance on previous studies. The areas of collagen expression were found to be decreased in the large and small airways, with tenascin and fibronectin expression both increased [10]. In that study, the use of tissue sections of $\geqslant 3 \mu \mathrm{m}$ thick to assess the area fractions of matrix proteins may have been variably over-estimated due to overlap of tissues components [7]. Therefore, the relative fractions of smooth muscle and extracellular matrix within the ASM layer in COPD remain unknown.

We aimed to address this using a stereological approach $[5,7]$ to relate the severity of airflow obstruction and history of smoking to the composition of the ASM layer including the number and size of ASM cells and the volume fraction of ECM.

We used tissue obtained from patients who have undergone lobectomy or pneumonectomy surgery (Perth, Australia, $n=30$; Vancouver, Canada, $n=9$ ), most often for the removal of a peripheral lung cancer. Participants performed spirometry before, and $15 \mathrm{~min}$ after, the inhalation of salbutamol (200-300 $\mu \mathrm{g})$ and completed a short health questionnaire to classify them as smokers (current or ex) or non-smokers (never smoked). Post-operatively, lung lobes were fixed by inflation with formalin and blocks of available airways (not required for pathological staging) were cut and processed for embedding in paraffin. Transverse sections of airways were cut at $0.5 \mu \mathrm{m}$ for estimation of ECM volume fractions (VVECM), within bundles of ASM defined at low power, using point counting on Masson's trichrome stained sections or $30 \mu \mathrm{m}$ thickness (haematoxylin) for morphometry and stereological assessment as previously described [5]. Perimeter of the basement membrane ( $\mathrm{pbm}$ ) was used as a marker of airway size.

Subjects were grouped based on a history of smoking and by airway size (small was defined by pbm $<5 \mathrm{~mm}$, and large by pbm $>5 \mathrm{~mm}$ ). Mean cigarette consumption for smokers was $44 \pm 41$ pack-years. In subjects where multiple airways were available, case mean values were used. Differences between groups were assessed using analysis of variance. Relationships between airway structure, lung function, pack years and duration of smoking, and numbers of cigarettes per day were examined using linear regression analysis. Analyses were undertaken using SigmaPlot 12.0 (Systat Software Inc, Erkrath, Germany).

In the present study we found that the VVECM within the layer of ASM was inversely related to a measure of airflow (forced expiratory volume in $1 \mathrm{~s}(\mathrm{FEV} 1))$. This relationship was present for all airways $(\mathrm{p}=0.002$, figure 1$)$ and for small $\left(p=0.009, r^{2}=0.176\right)$ and large $\left(p=0.003, r^{2}=0.280\right)$ airways analysed separately. FEV 1 $\%$ predicted was not related to other airway structures including ASM cell size and number. When smokers were analysed separately, the negative correlation remained between VVECM and FEV1 \% predicted in all airways combined $\left(p=0.008, r^{2}=0.233\right)$ and in large airways $\left(p=0.002, r^{2}=0.361\right)$ with a similar, non-significant trend in small airways $\left(\mathrm{p}=0.053, \mathrm{r}^{2}=0.132\right)$. These findings suggest that the increased ECM deposition within the layer of ASM may contribute to fixed airway narrowing in cigarette smokers. 


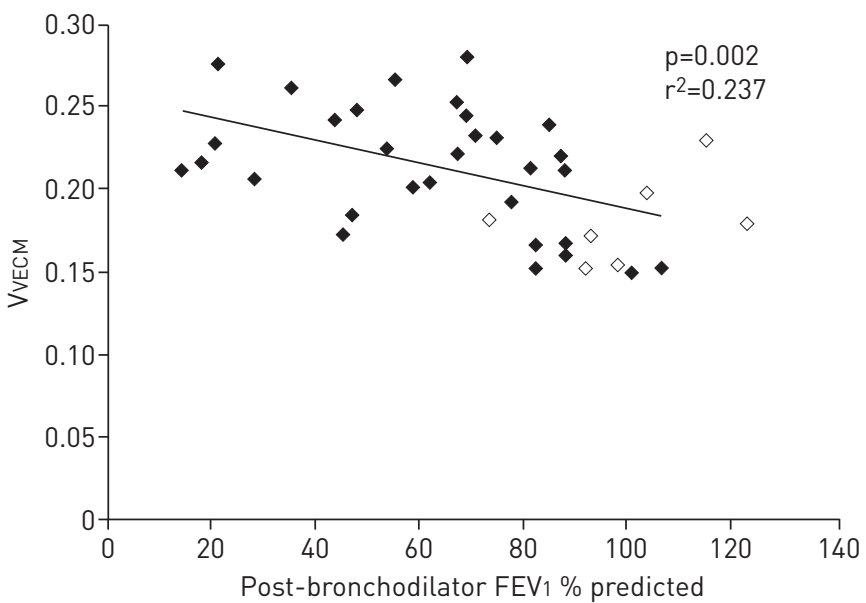

FIGURE 1 The relationship between the volume fraction of extracellular matrix (VVECM) within the smooth muscle layer and post-bronchodilator lung function (forced expiratory volume in $1 \mathrm{~s}$ (FEV $\left.V_{1}\right)$ for all airway sizes including both smokers (current and ex; closed symbols) and non-smokers (open symbols).

Smoking is a well-known factor in the development of COPD [11] and we found that the VVECM was increased in smokers (current smokers $\mathrm{p}=0.002$, ever-smokers $\mathrm{p}=0.023$ ) compared with non-smokers. However VVECM was not associated with the level of cigarette smoke exposure including the numbers of pack-years smoked $(\mathrm{p}=0.652)$, the duration of smoking $(\mathrm{p}=0.084)$ or number of cigarettes smoked per week $(\mathrm{p}=0.386)$. This is likely due to the relatively small size of our population due to selection bias since subjects were screened with regard to suitability for surgery. Although cigarette smoke exposure is strongly related to lung function decline [12], our study was not powered or designed to detect a dose effect of cigarette smoke on airway structure. This would require larger numbers of subjects. Nonetheless, since we did observe a relationship between smoking and reduced lung function (ever-smokers, $\mathrm{p}=<0.001$; ex-smokers, $\mathrm{p}=0.004$; current smokers, $\mathrm{p}=0.012$ ), a progressive deposition of ECM within the ASM layer is not excluded by our results.

Longitudinal studies in a general population show that lung function in smokers and non-smokers is similar at age 18 years, relatively early in the history of smoking [12]. Our data are consistent with the notion that the increase in ECM in the smooth muscle layer develops after the onset of smoking. However in clinical populations of patients with COPD, it is likely that both an increased rate of decline of FEV1 and long-standing (preceding the onset of smoking) airway remodelling contribute to reduced lung function [13]. This might confound the association between dose of cigarette smoke and remodelling, as we observed. In asthma there is a clear reduction in lung function in early adult life, compared with those without asthma $[12,14]$. In the COPDGene study [14], CT-assessed airway wall thickness was similar in subjects with COPD with or without a history of asthma [15] as was the degree of emphysema although the group with asthma had lower cigarette smoke exposure. These findings suggest that factors other than cigarette smoking may also contribute to airway wall thickness in subjects with COPD.

The results of the present study suggest that fixed airflow limitation involves an increase in the volume fraction of ECM within the ASM layer. COPD is defined by spirometry most commonly, but it is recognised that various pathologies may contribute to this functional abnormality. In smokers, narrowing of airways, loss of small airways and emphysema all contribute to reduced maximal expiratory flows [8]. Alterations of the volume fraction and type of ECM within the airway wall may affect function given the many roles of the ECM including sequestering water and cytokines, modulating secretory and contractile function of smooth muscle and direction of cellular traffic. The present study is compatible with the presence of progressive remodelling of the ASM layer resulting in increased ECM which may potentially restrict movement of the airway wall and may contribute to a poor bronchodilator response. Further studies with more careful phenotyping of subjects (airway versus parenchymal disease) with airflow obstruction over a larger age range are required. Finally, it is unknown if similar abnormalities are present in patients with fixed airflow obstruction associated with bronchiectasis, asthma or whether exposures other than cigarette smoke may also be involved.

0

$@$ ERSpublications

Remodelling of the layer of airway smooth muscle in COPD is characterised by an increase in the extracellular matrix http://ow.ly/YZqhz

Robyn L. Jones ${ }^{1,2}$, Peter B. Noble ${ }^{2,3}$, John G. Elliot ${ }^{1}$, Howard W. Mitchell ${ }^{2}$, Peter K. McFawn ${ }^{2}$, James C. Hogg ${ }^{4}$ and Alan L. James ${ }^{1,5}$ 
${ }^{1}$ Dept of Pulmonary Physiology and Sleep Medicine, Sir Charles Gairdner Hospital, Nedlands, Australia. ${ }^{2}$ School of Anatomy, Physiology and Human Biology, University of Western Australia, Australia. ${ }^{3}$ Centre for Neonatal Research and Education, School of Paediatrics and Child Health, University of Western Australia, Crawley, WA, Australia. ${ }^{4}$ Dept of Pathology and Laboratory Medicine, University of British Columbia James Hogg Research Centre, Institute for Heart and Lung Health, St. Paul's Hospital, Vancouver, Canada. ${ }^{5}$ School of Medicine and Pharmacology, University of Western Australia, Australia.

Correspondence: Robyn Jones, Department of Pulmonary Physiology and Sleep Medicine, Sir Charles Gairdner Hospital, Nedlands, Western Australia 6009. E-mail: robyn.jones@health.wa.gov.au

Received: June 222015 | Accepted after revision: Feb 042016 | First published online: March 172016

Support statement: Funding provided by the National Health and Medic al Research Council (NHMRC) of Australia (513842 and 1063068) and Sir Charles Gairdner and Osborne Park Health Care Group Research Advisory Committee and Charlies Foundation for Research (APP1045674). Peter B. Noble's salary was provided by a Career Development Fellowship from the NHMRC of Australia (1045824). Funding information for this article has been deposited with FundRef.

Conflict of interest: Disclosures can be found alongside the online version of this article at erj.ersjournals.com

Acknowledgements: Funding provided by the National Health and Medical Research Council (NHMRC) of Australia (513842 and 1063068) and Sir Charles Gairdner and Osborne Park Health Care Group Research Advisory Committee and Charlies Foundation for Research (APP1045674). Peter B. Noble's salary was provided by a Career Development Fellowship from the NHMRC of Australia (1045824).

\section{References}

1 Hogg JC. Pathophysiology of airflow limitation in chronic obstructive pulmonary disease. Lancet 2004; 364: 709-721.

2 James AL, et al. Airway smooth muscle thickness in asthma is related to severity but not duration of asthma. Eur Respir J 2009; 34: 1040-1045.

3 Ebina M, Takahashi T, Chiba T, et al. Cellular hypertrophy and hyperplasia of airway smooth muscles underlying bronchial asthma. A 3-D morphometric study. Am Rev Respir Dis 1993; 148: 720-726.

4 Woodruff PG, Dolganov GM, Ferrando RE, et al. Hyperplasia of smooth muscle in mild to moderate asthma without changes in cell size or gene expression. Am J Respir Crit Care Med 2004; 169: 1001-1006.

5 James AL, Elliot JG, Jones RL, et al. Airway smooth muscle hypertrophy and hyperplasia in asthma. Am J Respir Crit Care Med 2012; 185: 1058-1064.

6 Ebina M, Yaegashi H, Chiba R, et al. Hyperreactive site in the airway tree of asthmatic patients revealed by thickening of bronchial muscles. A morphometric study. Am Rev Respir Dis 1990; 141: 1327-1332.

7 Jones RL, Elliot JG, James AL. Estimating airway smooth muscle cell volume and number in airway sections. Sources of variability. Am J Respir Cell Mol Biol 2014; 50: 246-252.

8 Hogg JC, Chu F, Utokaparch S, et al. The nature of small-airway obstruction in chronic obstructive pulmonary disease. N Engl J Med 2004; 350: 2645-2653.

9 Kranenburg AR, Willems-Widyastuti A, Moori WJ, et al. Enhanced bronchial expression of extracellular matrix proteins in chronic obstructive pulmonary disease. Am J Clin Pathol 2006; 126: 725-735.

10 Annoni R, et al. Extracellular matrix composition in COPD. Eur Respir J 2012; 40: 1362-1373.

11 Buist AS, McBurnie MA, Vollmer WM, et al. International variation in the prevalence of COPD (the BOLD Study): a population-based prevalence study. Lancet 2007; 370: 741-750.

12 James AL, Palmer LJ, Kicic E, et al. Decline in lung function in the Busselton health study: the effects of asthma and cigarette smoking. Am J Respir Crit Care Med 2005; 171: 109-114.

13 Decramer M, Janssens W, Miravitlles M. Chronic obstructive pulmonary disease. Lancet 2012: 1341-1351.

14 Sears MR, Greene JM, Willan AR, et al. A longitudinal, population-based, cohort study of childhood asthma followed to adulthood. N Engl J Med 2003; 349: 1414-1422.

15 Hardin M, Silverman EK, Barr RG, et al. The clinical features of the overlap between COPD and asthma. Respir Res 2011; 12: 127.

\section{An outreaching model of tertiary difficult asthma care reduces adverse asthma outcomes and healthcare utilisation costs}

To the Editor:

Difficult asthma is a heterogeneous state, pragmatically defined by the British Thoracic Society (BTS) as "persistent symptoms and/or frequent exacerbations despite treatment at step 4 or step 5 treatment" $[1,2]$. 